well to read Dr. F. Lipmann's article on this subject. Use of the isotope technique has thrown acetic acid into prominence as a probable source, in the body, of complex organic molecules. Lipmann's work on acetyl phosphate shows a possible way in which acetic acid is likely to enter into the synthetic operations of the cell.

Limitations of space forbid more than mention of the interesting article by Dr. K. C. D. Hickman and Dr. P. L. Harris on tocopherol interrelationships, in which they examine the physiological activities of the $\mathbf{E}$ vitamins in terms of oxidation control and conclude that $\alpha$-tocopherol has a more fundamental function, at present not understood. Nor is there room to describe the lengthy (79 pages, 355 references) but most instructive article by Dr. Frankenburg on the chemical changes in the harvested tobacco leaf. Indeed, this article deals only with those changes attending the curing process; a later article will deal with the changes taking place during fermentation.

J. H. Quastel

\section{MATHEMATICS OF STATISTICS}

\section{Mathematical Methods of Statistics}

By Prof. Harald Cramér. (Princeton Mathematical Series, 8.) Pp. xvi+575. (Princeton, N.J. : Princeton University Press; London: Oxford University Press, 1946.) 33s. 6d. net.

\section{A First Course in Mathematical Statistics}

By Prof. C. E. Weatherburn. Pp. $x v+272$. (Cam. bridge : At the University Press, 1946.) 15s. net.

7 HESE two books at once invite comparison with Maurice Kendall's "Advanced Theory of Statistics" and A. C. Aitken's "Statistical Mathematics". All four are mathematically flawless, and they all require from the reader some mathematical training and ability, but not to the same extent, nor are they all addressed to quite the same category of scientific workers. Kendall, in his preface, called his "a book on statistics, not on statistical mathematics" and declared his intention "to keep the mathematics to heel". Cramér's book (based on his Stockholm lectures since 1930) is very definitely for the mathematician, and its avowed purpose is to join the two lines of development due on one hand to the British and American schools of statisticians, and on the other to the rigorous work of French and Russian mathematicians in developing the calculus of probability. The first twelve chapters are a purely mathematical introduction, dealing with the properties of sets, Lebesque integrals, Fourier integrals, matrices and quadratic forms, and the like, preparatory to the later chapters on random variables, probability distributions, and statistical inference. The author advises the reader to jump to Chapter 13 after reading the first three chapters and a few other paragraphs, and thereafter to use this earlier part only as needed. The advice is good, and for my part I would say jump to Chapter 13 at once. Many who ought to read the book would be highly discouraged by the apparent irrelevance of those first three chapters, yet might turn to them without dismay later after seeing their use and necessity.

Weatherburn says in his preface, "the subject treated in the following pages is best described not as Statistical Methods but as Statistical Mathematics, or the mathematical foundations of the interpretation of statistical data". His book does not make such demands on mathematical ability as Cramér's, and is addressed more to practitioners. It is indeed based on lectures to graduates and undergraduates whose researches and studies were in agriculture, biology, economics, psychology, physics and chemistry. They cannot, however, have been a random sample of the students of those disciplines, I imagine. For those who can follow, however, Weatherburn's book is excellent. The chapter on the properties of Beta and Gamma functions, the use of which in discussing tests of significance is a feature of the book, thoroughly justifies the author's claim that it is clear and simple and does not demand any previous knowledge of these functions. Moment-generating functions are used quite a lot (as also by Aitken), in contrast to Cramér's book, wheréthey are never mentioned except possibly in one exercise. I am surprised that the psychologists at least among Weatherburn's hearers did not ask for an earlier treatment of partial and multiple correlation. When he does come to them, he deals very neatly with the maximum eorrelation between one variable and the weighted sum of two others, and then simply directs attention to the valid. ity of the argument also for $n$ others. He does not mention, however, the problem of maximum correlation between two 'batteries' of variables, nor refer anywhere to Harold Hotelling. Neyman, too, receives only a passing reference, in a footnote, and Egon Pearson the same.

I mention these facts about Weatherburn's book not to criticize, but to assist the reader in knowing what to expect in it. Its great virtue is its compactness of argument, which facilitates seeing the whole. For example, he deals with fiducial limits in two paragraphs only, for the fiducial limits of a mean, using $\sigma$ in the earlier paragraph, and its unbiased estimate $s$ in the later; but the principle is shown clearly, though the words "fiducial limits, or confidence limits" on p. 122 rather suggest a confusion of the theories of Fisher and of NeymanPearson. Similarly, the term 'maximum likelihood' occurs only once in the book; but the paragraph which contains it (par. 77) puts the matter with extreme clearness. It may be, however, that anyone not knowing of its importance beforehand would pass over the paragraph without full appreciation. That is the danger of compactness and austerity. Kendall's book is warmer and more inviting.

In his Chapter 34, Cramér, after mentioning the two modern methods of outflanking Bayes' postulate, Fisher's fiducial probabilities and Neyman's confidence intervals, confines his treatment in the main to an account of the latter theory. In the succeeding chapter, on the general theory of testing statistical hypotheses, he deals further with the NeymanPearson theory and its basic idea of trying to reduce the chances both of rejecting a hypothesis when in fact it is true, and of accepting it when it is false.

On p. 520 Cramér begins a three-page discussion of the problem which leads to the Behrens test, namely, the problem of determining, from two independent samples, whether the means of two populations differ significantly, their standard deviations being also unknown and not necessarily equal. This is described, in Kendall's book, as a crucial problem for the rival theories of fiducial probability and confidence intervals. I speak with great diffidence, for the matter is difficult; but there does not appear to be any recognition of this in Cramér's book. 